\title{
Interview With Joe Freidhoff: A Bird's-Eye View of K-12 Online Learning
}

\author{
Leslie Pourreau \\ Kennesaw State University
}

Welcome to the interview portion of this special issue of the OLC Online Learning journal. Our intent is to introduce our long-time Online Learning readership to the field of K-12 online learning while also providing direction for our K-12 online learning scholars about where the field is going or should be going in terms of meeting the needs of K-12 stakeholders. We recently sat down with Dr. Joe Freidhoff, executive director of the Michigan Virtual Learning Research Institute, and asked him to provide us with his perspective on this ever-changing field.

\section{What can you tell us about your background and your position at the Michigan Virtual Learning Research Institute?}

My background is in English education. I taught high school English for three years in a local public school and a charter school before going to graduate school. I attended Michigan State University and earned a $\mathrm{PhD}$ in educational psychology and educational technology. During my time there, I gained teaching experience at the undergraduate and graduate levels in face-to-face and online settings. In 2009 after graduating from Michigan State, I began working at Michigan Virtual University. MVU is a private, nonprofit organization that works to advance K-12 education through digital learning, research, innovation, policy, and partnerships. I have worked in various capacities at MVU and currently serve as the executive director of the Michigan Virtual Learning Research Institute, which is housed at MVU. Our institute seeks to conduct research to better inform policy and practice aimed at improving the performance of students engaged in K-12 online and blended learning. The aim is to gain a richer, more contextualized understanding of what is happening in Michigan. We work to take what happens in the state of Michigan with K-12 online learning and promote its applicability to a greater context through connections with colleagues across the country and around the world. Earlier this year, we released our second annual report detailing the effectiveness of K-12 online learning in Michigan (Freidhoff, 2015). In addition to authoring this report, I present report highlights at state and national conferences, to key educational organizations, and to the Michigan legislature.

\section{For those new to K-12 online learning, could you define the scope of the field?}

Our field has grown immensely in the last decade. For me, K-12 online learning involves a myriad of places, pedagogies, professional learning, and policy. Places have a variety of meanings given that K-12 online learning looks different from state to state as well as within a state. Some states have full-time public schools where students can receive $100 \%$ of their instruction online. Some have supplemental state-supported virtual schools where students enroll in their local brick-and-mortar school but also may take online courses provided by the virtual school as part of their course schedule. Some 
states have both. Sometimes students take online courses at their local school building, and sometimes they engage in online learning away from campus. The history of K-12 online learning mostly has centered on high school and, to a degree, middle school, and predominantly for supplemental contexts. As full-time options have become more available, the K-6 and K-8 enrollments have started to increase. These are just a few examples of how place plays out in K-12.

K-12 online learning also looks at how students learn and are taught in online environments. From course design aspects to content-specific pedagogies, the field works to better understand how to efficiently and effectively design and deliver high-quality instruction to students. This has tended to include work around personalized learning and competency-based education. The interaction of technology, pedagogy, and content has necessitated professional learning for teachers and other school staff who work to support online learners and online learning programs.

On the policy side, frequent state issues include teacher credentialing and reciprocity, the number and size of full-time statewide cyber schools, funding models for online learning, and a student's right to choose online courses - often referred to as course choice or course access. Each state views these issues differently, which results in a differentiated set of rules and requirements across the United States. Districts also have their own sets of policies governing online learning and learners. These policies, both state and local, shift constantly, making it a career just to keep up with this area of K-12 online learning.

\section{If you were to recommend three or four seminal pieces in the field, what would they be and why are these so important to the field?}

Cathy Cavanaugh was the lead author on two meta-analyses from the early 2000s that compared K-12 distance and online learning with traditional K-12 schooling (Cavanaugh, 2001; Cavanaugh, Gillan, Kromrey, Hess, \& Blomeyer, 2004). These works were seminal in that they provided evidence that online or distance delivery methods could be as effective as traditional methods for K-12 students. While both works provided validation to the field, they also presented a challenge: The number of existing studies was and still remains small, and little was known about why or under what conditions K-12 students succeeded or failed when they moved into online environments.

In the mid-2000s, Kerry Rice (2006) published a comprehensive literature review on K-12 distance education that addressed the aforementioned comparison studies and field policy while also delving into areas such as learner characteristics, learner supports, and the affective domain. It remains a good primer on the challenges and opportunities that K-12 online research offers.

My third recommendation groups together several publications under the heading of iNACOLrelated works. iNACOL is the International Association for K-12 Online Learning and is one of the key trade organizations in this field. iNACOL publishes reports that are important to K-12 online learning in that they identify trends and directions for the field by covering topics such as access and equity, at-risk learners and online education, national standards, blended programs, quality assurance, and competencybased education. One example of an iNACOL-related work is the Keeping Pace report released yearly at the annual iNACOL conference by John Watson and his Evergreen Education Group. Although not an iNACOL publication, this report is one of the most heavily cited pieces in our field, especially when it comes to documenting the size and growth of K-12 online learning. It provides state-by-state profiles, updated on an annual basis, and identifies key trends in the field of K-12 online learning. Keeping Pace has documented much of the history of K-12 online learning; it will release its 12th edition in November 2015.

Lastly, recent publications like Rick Ferdig and Kathryn Kennedy’s (eds.) Handbook of Research on K-12 Online and Blended Learning and Tom Clark and Michael Barbour's (eds.) Online, Blended, and Distance Education in Schools: Building Successful Programs have addressed a range of K-12 online 
learning topics by bringing together in one collection key works written by a who's who of key researchers. Additionally, the Michigan Virtual Learning Research Institute maintains the Research Clearinghouse for K-12 Blended and Online Learning (http://k12onlineresearch.org), where interested readers can find many more publications from the field of K-12 online learning.

\section{Considering research in K-12 online learning, what can we say we know about the field?}

K-12 online enrollment has increased dramatically over the last decade. Michigan went from about 185,000 online enrollments in 2012-13 to over 319,000 one year later. Nationally, there is likely a total of 5,000,000-7,000,000 online enrollments in full-time and supplemental programs combined, if not more. K-12 online learning is growing at a rate that clearly outpaces the research we have about it. I think language from a recent Institute of Education Sciences grant (U.S. Department of Education, 2015) sums up the research need quite succinctly:

Given the omnipresence of technology in modern life, it may be that the most pertinent research questions have less to do with the effectiveness of online and blended learning relative to traditional (i.e., nontechnological) modes of instruction and more to do with understanding how to improve delivery so that more students derive greater benefit. (p. 11)

The idea of improving delivery to increase student benefit is so vital, since students enroll in online courses for a variety of reasons ranging from face-to-face course scheduling conflicts to retaking courses in an online format to recover credits from failing grades. We know that students who take online courses to resolve scheduling or unavailability issues with face-to-face courses tend to have higher pass rates than students who enroll in online courses out of learner preference and credit recovery, yet the students who struggle in face-to-face courses tend to be viewed as the prime candidates for online learning. In my mind, there is a disconnect between what we know and what we practice. We know that online students tend to be more successful when they have strong time management skills, know how to set goals, have regular attendance, and enter a course having a solid foundation in the prerequisite knowledge, skills, and attitudes of the subject, et cetera - traits similar to successful face-to-face learners. The challenge is that schools often enroll online students who have significant weaknesses in one or more of these areas, so the learner traits we directly relate to high success are not necessarily those of the students typically being enrolled.

We know online learning can work. Many programs succeed by combining disciplined student selection and preparation with systems of local support, engaging parents in the online learning process, and choosing or creating high-quality course content taught by skilled online learning instructors; however, we can also point to many programs that fail despite using these same combinations. A key challenge for K-12 online learning researchers is to effectively tease out the traits of successful programs for replication with fidelity at other institutions.

Finally, we know that teacher preparation programs do not adequately prepare teachers to teach in online environments, and very few offer preservice practicum teaching experiences housed in fully online environments. Clearly, high-quality teachers are one of the key leverage points for improving online delivery, and we need more research and better training for those who teach online.

\section{What challenges do K-12 online learning scholars face?}

Many researchers in our field are faculty at institutions of higher education who must navigate the tenure and promotion process, which includes publishing. Most publications end up in highly-ranked, peer-reviewed journals, many of which do not offer open access. A challenge facing all researchers is publishing high-quality research that is accessible and applicable by K-12 online learning practitioners. We need to help practitioners steer the students best suited for online learning and also help them create 
educational systems that afford students the most applicable and appropriate support systems for their learning needs and contexts. Doing this involves reducing the amount of time it takes to move from theory into practice given the large number of students being educated through online learning. Researchers need to use more widely accessible forums to expand the theories and knowledge of our research base in the field. Publishing in open journals such as this one would be a start.

Our field is one of big data and rich description. We increasingly capture an abundance of metadata about student interactions and pathways through the learning management systems that deliver online courses, but there are critical data points that go uncaptured and will remain uncaptured by these systems. The challenge here for scholars lies in developing proficiency in mixed methods approaches to research. Developing the skill set to analyze millions of data points competently while simultaneously providing rich, qualitative analysis of the off-line contexts and the online interactions takes time and a commitment to ongoing professional development.

In this same vein, another challenge for scholars in our field is developing relationships with researchers from other disciplines, including those who focus on online learning and adults, or online learning and higher education. Developing more interdisciplinary research teams will benefit our field and others by generating new questions, applying new methods, discovering new insights, and guarding against group thinking.

The central challenge we have as K-12 online learning researchers is improving student learning. We need research that moves us closer to the potential that online learning advocates proclaim. Proponents see online learning as a way to bring highly skilled teachers to students so that zip codes cease to define educational opportunities, a way to educate students anytime and anywhere. We need research to help make that a reality. Despite notions of anytime-anywhere learning, time and routine are critical factors in student success, and the location and settings in which they work matter. We need more research to better inform time-and-place decisions. I mentioned earlier that online learning is seen as having the potential to help students recover credits which they have failed, but it also is expected to help close the gaps for low-income students. In Michigan last year, 64\% of the K-12 online enrollments came from students in poverty, but only $53 \%$ of them were successfully completed. We need more research on better serving at-risk populations, who make up a large percentage of current online learning students.

\section{Where do you see K-12 online learning in 20 years, and how should research help shape this vision?}

I doubt I have a good vision of what technologies are going to exist in 10 years let alone 20, but I'm willing to speculate. Today, I think schools, students, and parents turn to online learning when something goes wrong with the traditional model - a course the student wants to take is not offered at the school, the student can't take the course at the hour it is offered, or the student has fallen behind and needs to make up the credit. To that extent, I think we are still at the stage where K-12 online learning occurs at the fringe.

Over the next 20 years, preferably much sooner, I think schools—some because of educational beliefs and others because of parent and student pressure-will integrate online learning as one of multiple flexible-learning options provided to best serve the needs of diverse student populations. Many "traditional” courses will blend substantial online content into their delivery, and schools will continue to offer à la carte versions of online courses to supplement local offerings. Full-time online schools will continue to grow and educate significant numbers of students, but the majority of students who participate in online learning will do so in a supplementary manner. I think we will have moved beyond the face-toface versus online learning mindset and will be talking more about how the two complement rather than compete against each other.

In twenty years, I believe that longitudinal data systems at the local and state levels will be better; I doubt this will happen at the national level. Statewide systems will provide much richer detail and 
greater transparency of outcomes. We will have more advanced early warning and ongoing monitoring systems that will allow for quick intervention to better ensure student success in a course.

Researchers will play a vital role in shaping the future of K-12 online learning. A considerable threat to the vision I laid out is that well-intentioned schools frequently enact poorly designed online learning programs. The experiences of those impacted by such programs-school administrators, teachers, students, and parents-confirm or create beliefs that online learning doesn't work, even if counterparts in other schools are proving otherwise. We have a significant research need to expand our understanding of how to create highly successful online learning programs, how to communicate this understanding in ways that influence K-12 schools' program designs, and how to bring these kinds of programs to scale. Researchers help shape the kinds of conversation that take place as well as who participates in them. The research that we as a field conduct must help audiences that include course designers, school administrators, school teachers, on-site facilitators, students, parents, and policy makers take action to improve current efforts so that the reality of what online learning offers comes closer to meeting its potential.

Correspondence: Leslie Pourreau is a doctoral candidate in the Department of Instructional Technology at Kennesaw State University, in Kennesaw, Georgia. She has written and presented about subjects such as K-12 female educator identity and change, technology and empowerment, and online professional development in virtual school settings. She can be reached at lap6562@kennesaw.edu or pourreaul@gmail.com.

\section{References}

Cavanaugh, C. (2001). The effectiveness of interactive distance learning technologies in K-12 learning: A meta-analysis. International Journal of Educational Telecommunications, 7(1), 73-78.

Cavanaugh, C., Gillan, K. J., Kromrey, J., Hess, M., \& Blomeyer, R. (2004). The effects of distance education on K-12 student outcomes: A meta-analysis. Naperville, IL: Learning Point Associates. Retrieved from http://faculty.education.ufl.edu/cathycavanaugh/docs/EffectsDLonK12Students1.pdf

Clark, T., \& Barbour, M. K. (Eds.). (2015). Online, blended and distance education in schools: Building successful programs. Sterling, VA: Stylus Publishing.

Ferdig, R. E., \& Kennedy, K. (Eds.). (2014). Handbook of research on K-12 online and blended learning. ETC Press. Available under Public License from http://press.etc.cmu.edu/content/handbookresearch-k-12-online-and-blended-learning-0

Freidhoff, J. R. (2015). Michigan's K-12 virtual learning effectiveness report 2013-14. Lansing, MI: Michigan Virtual University. Retrieved from http://media.mivu.org/institute/pdf/er_2014.pdf

Rice, K. L. (2006). A comprehensive look at distance education in the K-12 context. Journal of Research on Technology in Education, 38(4), 427-449. Retrieved from http://www.eric.ed.gov/PDFS/EJ768723.pdf

U.S. Department of Education, Institute of Education Sciences. (2015). Request for applications: Education research and development center program (CFDA Publication No. 84.305C). Retrieved from http://ies.ed.gov/funding/pdf/2016 84305C.pdf 